\title{
REFLEXÕES SOBRE O PROCESSO FORMATIVO DE DOCENTES EM CONTEXTOS MEDIADOS PELA LÍNGUA \\ ESCRITA
}

\section{REFLECTIONS ON THE FORMATIVE PROCESS OF HISTORY TEACHERS IN CONTEXTS MEDIATED BY WRITTEN LANGUAGE}

\begin{abstract}
RESUMO: O presente trabalho se propõe a relatar e analisar uma experiência de formação continuada, no formato de curso de extensão, voltada a professores da rede municipal de Campos dos Goytacazes/RJ, e ocorrida no âmbito do projeto de pesquisa "Experiências da modernidade na arte e na política". A experiência foi realizada em 2014/2015, atendendo a 30 assistentes. No projeto, considerou-se que os saberes docentes são temporais, variados e heterogêneos, situados e personalizados, concepção que torna possível vislumbrar esses saberes como elemento central dos processos formativos. Além disso, pressupõe-se que os professores não se limitam a executar currículos, mas também os elaboram, definem e reinterpretam a partir do que pensam, do que acreditam e valorizam, destacandose, nesse contexto, o papel do registro escrito enquanto instrumento cultural de aprendizagem. No texto, coloca-se em relação produções visuais e textuais de um dos docentes do curso, destacando-se a relação de diálogo do sujeito com seus saberes de maneira consciente e mediada pela escrita no contexto de produção de várias versões de um plano de aula. As conclusões apontam o potencial formativo da escrita quando compreendida a natureza dialógica, responsiva e autoconstitutiva da linguagem no desenvolvimento das reflexões dos docentes sobre a natureza do conhecimento histórico escolar.
\end{abstract}

Palavras-chave: Ensino de história. Formação de professores. Língua escrita.

\begin{abstract}
The present work intends to report and analyze an experience of continuous training, in the format of an extension course, addressed to teachers of the municipal education system of Campos dos Goytacazes / RJ, and occurred within the scope of the research project "Experiences of modernity in art and in politics". The experience was carried out in 2014/2015, attending 30 assistants. In the project, it was considered that the teaching knowledge is temporal, varied and heterogeneous, situated and personalized, conception that makes it possible to glimpse this knowledge as a central element of the formative processes. In addition, it is assumed that teachers are not limited to executing curricula, but also elaborate, define and reinterpret them from what they think, what they believe and value, and in this context the role of writing as a cultural learning instrument. In the text, visual

\footnotetext{
${ }^{1}$ Docente da Faculdade de Educação da Universidade Federal do Mato Grosso do Sul. Doutora em Educação pela Universidade de São Paulo.
} 
and textual productions of one of the course lecturers stand out, highlighting the dialogue relationship of the subject with his knowledge in a way that is conscious and mediated by writing in the production context of several versions of a lesson plan. The conclusions point to the formative potential of writing when understood the dialogic, responsive and self-constitutive nature of language in the development of teachers' reflections on the nature of school historical knowledge.

Keywords: History teaching. Teacher training. Written language.

\section{Apresentação}

Os cursos de extensão oferecidos por diferentes universidades têm sido considerados espaços importantes de formação docente em serviço. A demanda social por este formato de ação é alta e pode ser conferida pelas inúmeras ações oferecidas, sejam presenciais ou à distância. Tal demanda é, muitas vezes, justificada por necessidades relacionadas ao desejo de incremento dos saberes docentes, que são imbuídos da tarefa de frequentar os cursos referidos na maior parte do tempo fora de seu horário de trabalho.

Seguindo essa tendência, o curso de extensão intitulado "Ensino de História e a fotografia como linguagem, fonte histórica e recurso didático" 2 foi organizado pela autora a partir de uma demanda por parte da Secretaria Municipal de Educação (SEMED), da cidade de Campos de Goytacazes, ao setor de Prática de Ensino do curso de História da Universidade Federal Fluminense (UFF) solicitando uma formação de 30 horas aos seus docentes. O tempo exíguo disponibilizado evidencia o caráter contraditório à lógica da formação na perspectiva do intelectual crítico reflexivo e, por isso, colocouse como um desafio a mais no contexto da temática abordada.

Assim, surgiram algumas indagações a partir do conhecimento acadêmico em torno de práticas de formação no campo do Ensino de História,

\footnotetext{
${ }^{2}$ Refere-se ao curso de formação oferecido pelo Laboratório de Estudos e Pesquisas sobre Ensino de História (LABORA/UFF), coordenado pela autora, realizado em parceria com a Secretaria Municipal de Educação, Cultura e Esportes (SMECE), da Prefeitura da cidade de Campos dos Goytacazes (RJ), e financiado pelo Laboratório História, Política e Cultura (LAHPOC), coordenado pela profa. Dra. Débora El-Jaick Andrade, docente de Teoria da História do curso de História/UFF/Campos. O curso fez parte das ações de extensão vinculadas ao projeto de pesquisa intitulado "Experiências da modernidade na arte e na política", coordenado pela profa. Débora e financiado com recursos do Edital Faperj $n^{\circ}$. $21 / 2012$.
} 
a saber: quais contribuições um curso de formação continuada de curta duração pode oferecer ao docente sobre uma temática tão complexa como a do trabalho com imagens no Ensino de História? Como os professores podem fomentar a mobilização de conhecimentos pedagógicos na transformação de suas práticas, em diálogo com conhecimentos historiográficos e desenvolver instrumentos de análise dos próprios saberes? Que papel o registro escrito poderia ter nesse tipo de situação, tendo-se em vista a natureza dialógica, responsiva e auto-constitutiva da linguagem?

Considerando princípios da pesquisa qualitativa em Educação (LAVILLE, 1999; POUPART, 2010), empreendeu-se a análise de produções ${ }^{3}$ de um docente participante do curso. Frente às indagações apresentadas anteriormente, objetivou-se sistematizar alguns dos indícios da reflexão tecida pelo professor Mauro ${ }^{4}$ no decorrer do trabalho de parceria estabelecido e que indicam pistas dos saberes empreendidos e construídos no diálogo mediado, por um lado, pelo conhecimento histórico e didático sobre os usos de imagens na História e em seu ensino, e, por outro, pela língua escrita em sua dimensão de prática de linguagem e em seu componente de experiência.

\section{Saberes, diálogos, descobertas}

Os professores que atenderam ao curso de extensão indicado anteriormente mencionaram que estavam ali em buscas de "técnicas" que Ihes permitissem melhor enfrentar os desafios do ensino na sala de aula. Em suas próprias palavras, buscavam "novas maneiras de ensinar" para "tornar as aulas mais dinâmicas"5. Esse sentido do que significa se atualizar traz embutida uma concepção muito reforçada pela universidade de que os

\footnotetext{
${ }^{3}$ Foi coletado e analisado um conjunto de produções de cinco docentes participantes do curso. A autora agradece imensamente a esses colegas pela generosidade com que contribuíram com o trabalho de pesquisa, cedendo suas produções e atendendo às demandas de entrevistas.

${ }^{4} \mathrm{~A}$ fim de manter o anonimato do docente em questão, refere-se ao mesmo como Mauro, um nome fictício, conforme orientações do Comitê de Ética em Pesquisa com Seres Humanos.

${ }^{5}$ Anotações em caderno de campo da conversa realizada com 15 professores (com formação e atuação em sala de aula nas disciplinas de História, Artes, Geografia e Português) no $1^{\circ}$ encontro do curso $(19 / 03 / 14)$ que teve como objetivo mapear as demandas formativas que os mesmos apresentavam ao curso.
} 
professores da Educação Básica precisam incrementar sua formação intelectual, procurando cursos e estudando fora de seu ambiente de trabalho, compreendendo a prática profissional como uma resolução instrumental de problemas baseada na aplicação de teorias e técnicas científicas construídas em outros campos, ou seja, em uma perspectiva da racionalidade técnica do saber (TARDIF; RAYMOND, 2000). O pressuposto tácito subjacente a essa concepção é de que o professor é um técnico, habilitado para ensinar o que é pré-determinado pelos programas e currículos, sendo possuidor, portanto, de uma competência técnica que lhe permite ensinar os conhecimentos científicos que os alunos precisariam aprender. Em adição, concebe-se o docente como aquele que, fundamentalmente, é o responsável por veicular conhecimentos produzidos e referendados cientificamente pelas diferentes áreas de conhecimento (MONTEIRO, 2003).

Cabe ressaltar a relação dessa perspectiva com o contexto das políticas neoliberais que, dadas as novas configurações do trabalho, o não-emprego, descartando as conquistas trabalhistas, impõe a necessidade de o trabalhador buscar, por sua conta, requalificações. Advém daí a imensa valorização conferida atualmente aos programas de formação continuada, transformando a educação em um grande mercado.

Balizadas por esses pressupostos, muitas ações de formação ofertadas parecem reforçar a crença de que o professor "precisa de" "algo" que o permita ensinar "melhor" e que esse "algo" pode ser conseguido no interior de um curso, o qual é concebido muitas vezes sem considerar elementos da cultura escolar e da cultura da escola, ocorrendo fora da instituição de origem do docente.

Na sistematização das demandas apresentadas pelos professores no primeiro encontro, foi possível identificar alguns indícios dos sentidos atribuídos por esses sujeitos à função das ações de formação em sua vida profissional, que parecem estar situados na relação ciência/técnica na acepção formulada por Larrosa (2002), inspirado em Walter Benjamin. Para esse autor, o par ciência/técnica remete a uma relação positiva e retificadora e, no campo da Educação, refere-se a um sujeito técnico, que aplica com maior ou menor eficácia diversas tecnologias pedagógicas produzidas pelos 
cientistas, pelos técnicos. O dado colocou-se como primeiro desafio no sentido de planejar atividades que pudessem mobilizar ${ }^{6}$ reflexões sobre a formação fundamentada na concepção do par experiência/sentido, em que os docentes participantes pudessem relacionar-se com suas demandas como saberes, e não como faltas. Dessa forma, foi importante ter em vista, a partir de Benjamin, que o sujeito da experiência é um sujeito "ex-posto", que se constitui no encontro, no tempo da apreciação, da escuta atenta, elementos em falta na modernidade e que desaparecem junto com o narrador (BENJAMIN, 1985). Larrosa (2002) chama a atenção para o que nos ensina a palavra "experiência", vinda do latim experiri, afirmando que ela é, em primeiro lugar, um encontro em que algo se experimenta, que se prova.

Apesar de o formato de cursos de extensão ser marcado pela concepção racionalista, fundamentou-se a ações, seja no planejamento, seja na coleta dos dados e análise, no pressuposto de que as reflexões que tomam lugar no decorrer do processo de reflexão do professor sobre o seu fazer são complexas e multifacetadas. A partir de Tardif (2000), concebe-se que os saberes docentes são temporais, variados e heterogêneos, situados e personalizados, concepção que torna possível vislumbrar esses saberes como elemento central dos processos formativos.

Amparada por esses referenciais, procurou-se estabelecer uma relação de formação que, em oposição (mas, necessariamente, em diálogo) se apresentasse como espaço de ressignificação do campo de ação profissional (CAIMI, 2008), uma vez que, ao tomarem sua prática como objeto de observação e de reflexão, compartilhando sentidos com outros sujeitos, engendram-se condições de possibilidades para que os professores

\footnotetext{
6 O conceito de mobilização utilizado é no sentido imputado por Charlot (2005). No contexto da crítica ao reprodutivismo da teoria de Pierre Bordieu sobre o habitus, o autor destaca que a análise das políticas educacionais, considerando posições sociais, é necessária, mas insuficiente, pois a sociedade é um conjunto de práticas e não só um conjunto de posições. Aqui menciona a importância da recuperação do conceito marxista de práxis operado por Vigotski, apontando que "as atividades são socialmente definidas, mas também são atividades de um sujeito" (CHARLOT, 2005, p. 19). Nesse contexto, o autor considera que o conceito de mobilização é mais significativo do que o de motivação, pois, pensando sobre o ensino, a questão mais importante não é saber como vou motivar o aluno, mas o que posso fazer para que o aluno se mobilize. "A mobilização é um movimento interno do aluno, é a dinâmica interna do aluno que, evidentemente, se articula com o problema do desejo" (CHARLOT, 2005, p. 19). Do ponto de vista da psicanálise, tem-se que o sujeito interpreta o mundo. $\mathrm{Na}$ análise empreendida apresentada neste artigo, compreendo o professor como esse sujeito.
} 
reconstruam o pensamento, embasados em novos patamares, em sucessivas tomadas de consciência da ação docente. Tal reconstrução, apoiada num sistema de relações e referências conceituais mais amplo, configura uma nova estrutura epistemológica, que possibilita ao professor um "pensar-fazer pedagógicos qualitativamente diferente do anterior" (AXT; MARASCHIN, 1999, p. 23 apud CAIMI, 2008, p. 264). A inserção dos professores nessa nova estrutura conceitual de referência filia-se "a uma nova rede de significações, condição de possibilidade para significar tanto a ação própria na instância local, quanto o próprio campo de atuação profissional em que a ação se atualiza" (CAIMI, 2008, p. 264).

Os dados que subsidiaram essa reflexão foram coletados no primeiro registro escrito dos participantes a respeito do que definiam por imagem (Produção 1 - P1). O registro produzido, que acionou um saber declarativo, retomado depois ao final do curso, estabeleceu um marco inicial para os trabalhos no decorrer dos encontros previstos, de maneira que os professores pudessem pensar e sistematizar por escrito seus saberes sobre a definição de imagem, conceito que tem sido objeto de reflexões filosóficas desde Platão e que se configurou como eixo norteador do curso e das atividades subsequentes. A seguir, apresentam-se algumas das respostas produzidas pelos docentes, a título de exemplo.

Quadro 1 - Exemplo de texto produzido pelos docentes - Produção 1 (1 $^{a}$ versão - produzida no $1^{\circ}$ encontro)

\begin{tabular}{|c|c|c|c|}
\hline Questão & J-P1 & L-P1 & MA-P1 \\
\hline $\begin{array}{l}\text { 1. O que é } \\
\text { imagem? }\end{array}$ & $\begin{array}{l}\text { É uma representação } \\
\text { visual de qualquer } \\
\text { coisa como por } \\
\text { exemplo um desenho, } \\
\text { uma figura, uma foto, } \\
\text { um cartão postal etc. }\end{array}$ & $\begin{array}{l}\text { É o que vemos ou } \\
\text { formulamos e que nos } \\
\text { permite uma } \\
\text { interpretação livre }\end{array}$ & $\begin{array}{lr}\text { É o resultado do } \\
\text { olhar de alguém que } \\
\text { fixou algo } & \text { naquele } \\
\text { momento e } & \text { espaço. } \\
\text { Quanto } & \text { mais } \\
\text { sensível } & \text { e } \\
\text { observador, } & \text { maior } \\
\text { será a } & \text { sua } \\
\text { possibilidade } & \text { de } \\
\text { captar. Esse registro } \\
\text { possibilitará } r \\
\text { outros, em que } \\
\text { tempo um } \\
\text { possa fazer a leitura } \\
\text { específica daquele } \\
\text { objeto que foi fixado }\end{array}$ \\
\hline
\end{tabular}




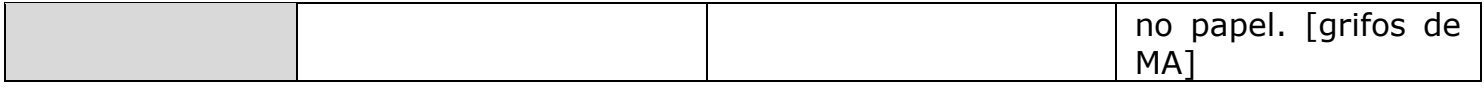

\section{Fonte: Autor.}

no papel. [grifos de

Complementarmente, os professores também registraram, no mesmo encontro, a definição de fotografia (Produção 2 - P2) e como achavam que ela poderia contribuir para o Ensino de História (Produção 3 - P3), conforme exemplos no quadro 2 a seguir.

Quadro 2 - Complemento do Quadro 1

\begin{tabular}{|c|c|c|}
\hline Professor(a) & $\begin{array}{l}\text { O que é fotografia? } \\
\text { Produção } 2 \text { - P2) }\end{array}$ & $\begin{array}{l}\text { Como a fotografia pode } \\
\text { ser utilizada no ensino de } \\
\text { História } \\
\text { (Produção } 3-\text { P3) }\end{array}$ \\
\hline MA & $\begin{array}{l}\text { "É o resultado do olhar de alguém que } \\
\text { fixou algo naquele momento e espaço. } \\
\text { Quanto mais sensível e observador, } \\
\text { maior será a sua possibilidade de } \\
\text { captar. Esse registro possibilitará que } \\
\text { outros, em um tempo posterior, possa } \\
\text { fazer a leitura específica daquele } \\
\text { objeto que foi fixado no papel". [grifos } \\
\text { da autora] }\end{array}$ & $\begin{array}{l}\text { "É uma fonte riquísssima de } \\
\text { trabalho do professor. É um dos } \\
\text { elementos auxiliares para uma } \\
\text { exposição em sala de aula. Ex.: } \\
\text { a capa do livro "O Cortiço" de } \\
\text { Aluízio Azevedo, já permite uma } \\
\text { compreensão de que o autor vai } \\
\text { tratar, pois os detalhes da foto } \\
\text { já nos permitem uma leitura dos } \\
\text { conflitos aí existentes (Rio de } \\
\text { Janeiro nos anos 20, } \\
\text { urbanização/pobreza, } \\
\text { deslocamento/agrupamentos } \\
\text { diferenciados etc.)". }\end{array}$ \\
\hline L & $\begin{array}{l}\text { "É a representação, real ou não, de um } \\
\text { momento, objeto ou paisagem". }\end{array}$ & $\begin{array}{l}\text { "Pode ser usada para análise e } \\
\text { interpretação de uma época, } \\
\text { identificação de espaços, etc.". }\end{array}$ \\
\hline
\end{tabular}

Fonte: Autor.

Longe de expressarem todos os saberes conceituais que os professores certamente possuíam, os escritos são ricos por trazerem indícios de diferentes olhares relacionados provavelmente à formação específica de cada professor (a turma era composta por professores de Artes, de Língua Portuguesa, de Geografia e de História, além de coordenadoras pedagógicas com formação em Pedagogia). Também foi uma produção importante porque pretendeu estabelecer um patamar inicial das discussões que tomariam lugar nos encontros seguintes, uma vez que as contribuições foram socializadas e sistematizadas em um só documento escrito produzido coletivamente. O papel mediador da escrita foi exacerbado no momento de socialização, pois o registro coletivo motivou a troca de ideias entre os participantes, que 
explicavam e buscavam palavras que expressassem melhor o que pretendiam registrar.

Com o intuito de obter mais dados sobre os sentidos mobilizados pelos docentes, propôs-se, também, no primeiro encontro, a realização de exercícios fotográficos solicitando-lhes que produzissem imagens de objetos/lugares do local onde o curso acontecia7 (Produção 4 - P4). Nesse contexto, um elemento desafiador que tinha a função de problematizar a ideia da imagem/verdade foi colocado: seria necessário captar objetos que, na realidade concreta, eram pequenos, mas que, na fotografia, deveriam criar a sensação de serem grandes. Além disso, a imagem teria que provocar a curiosidade, em seus apreciadores, de saber onde ela havia sido captada. 0 exercício resultou em imagens como os exemplares que seguem:

\section{Figura 1 - (MFA-P4) - Sem título (março de 2014)}

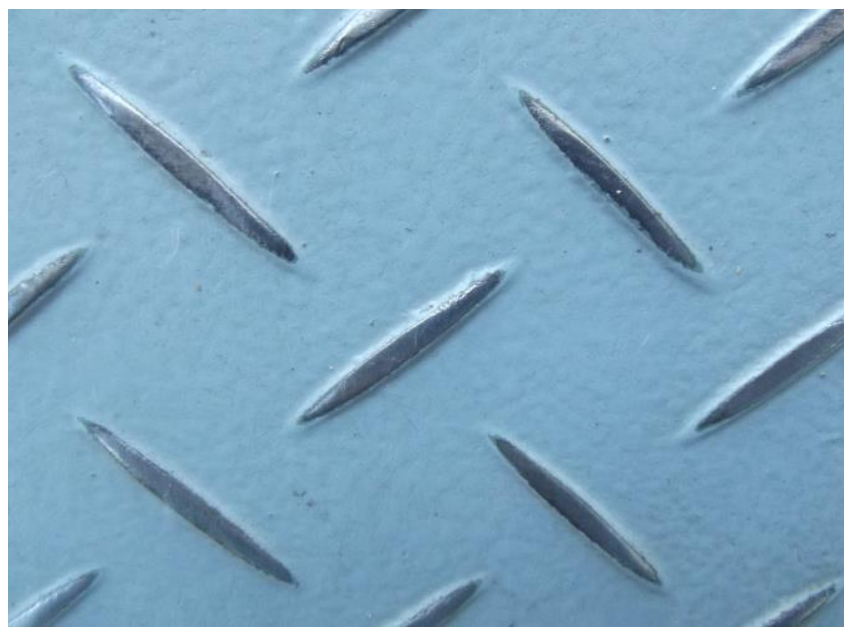

Fonte: Autor.

\footnotetext{
${ }^{7}$ No prédio do Instituto de Ciências da Sociedade e Desenvolvimento Regional da UFF, em Campos dos Goytacazes/RJ. Observe-se que a legenda das fotos indica um título. O mesmo foi elaborado pelo seu autor, atividade que também fez parte do processo de reflexão sobre a construção do Olhar.
} 


\section{Figura 2 - (AFA-P4) - Sementes (março/2014)}

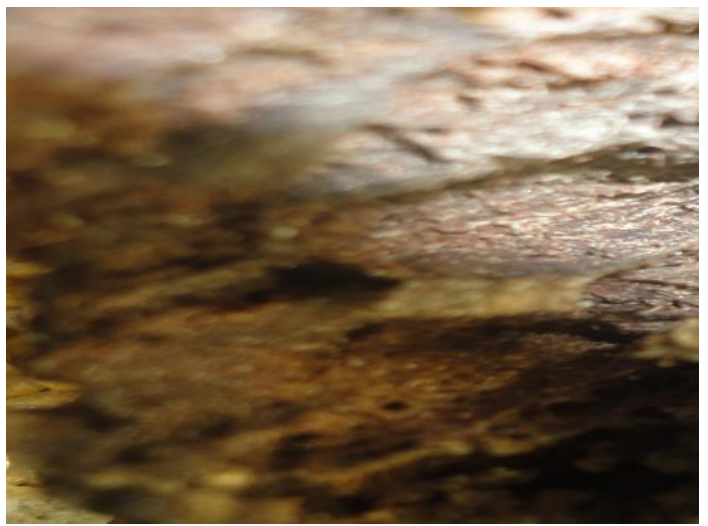

Fonte: Autor.

O exercício propiciou vislumbrar um conhecimento em ação relacionado aos conteúdos teóricos que, no curso, apareceriam relacionados tanto à historiografia, quanto à Sociologia e à Filosofia da imagem. A imagem 1 (MFA-P4 ${ }^{8}$ ) foi produzida por Mauro, cujo percurso foi analisado neste artigo. Observando a produção, é possível perceber conhecimentos de aspectos técnicos do uso da máquina fotográfica (abertura, enquadramento, foco); saberes sobre a relação sujeito que observa/autor-fotógrafo, uma vez que a imagem captada cria um desafio a quem a observa e anexa alusivos de diferentes ordens em sua leitura (Chão? Parede? Textura de ferro?); e conhecimentos sobre o estatuto de verdade da imagem e o acionamento de referentes que, nessa produção, remetem a uma pintura (traços em uma tela?) e, por isso, pôs em relevo elementos da subjetividade de sua produção pelo uso controlado da luz e da cor, bem como pelo cuidado ao decidir o que ficaria "dentro" e o que ficaria "fora" da imagem.

Reunidos na sala, o material produzido foi apreciado com a tarefa de descobrirem que objeto seria aquele e onde ele estava. O momento da projeção das imagens coletadas foi marcado por muita conversa e indagações. Os participantes riram, ficaram intrigados, ora identificando os objetos/lugares, ora surpreendendo-se quando o autor as identificava e os

\footnotetext{
8 Tendo em vista que os participantes produziram diversas fotos no decorrer de todo o curso, adotou-se essa sistemática de numeração para proceder à análise, considerando-as todas inseridas no contexto da Produção 2. Assim, teremos: MFA-P4 = Mauro Foto A; P4 - referese à sequência numérica das produções dos participantes (escritas e imagéticas), sendo P4 referente especificamente às fotos.
} 
demais expressavam com surpresa que "nunca pensariam naquilo" 9 . Naquele momento, uma série de memórias afetivas, familiares, vieram à tona, e lembranças foram compartilhadas pelo grupo, exacerbando-se o componente de experiência que norteou o trabalho. Foram lançadas, também, algumas questões que visavam trazer à consciência alguns conhecimentos que se faziam presentes de forma inconsciente (um saber da ação), tais como: de que lado vinha a luz, onde estava o fotógrafo e em que posição, e por que a imagem é capaz de acionar referentes conhecidos.

A atividade de realizar exercícios repetiu-se por quase todos os encontros, sempre com um desafio que os convidava a explorar um recurso técnico da produção fotográfica ao mesmo tempo em que se promovia a reflexão teórica sobre algum elemento da construção do Olhar. Também o momento de apreciação das produções tornou-se ritual ao início das reuniões sendo, em alguns momentos, veementemente cobrado pelos participantes, os quais se ressentiram dos dois encontros que não pudemos realizar.

A partir dos textos e imagens produzidos, bem como dos dados que foram registrados em cadernos de campo da conversa do grupo sobre as fotografias, pôde-se perceber, a grosso modo, que as representações trazidas por alguns professores sobre o papel das imagens no ensino (perspectiva da ilustração) não condiziam com os saberes apresentados nas fotografias produzidas na atividade inicial, indicando que os saberes manifestos na dimensão da ação pareciam não ser "automaticamente" mobilizados na reflexão sobre a prática docente. As fotografias possibilitaram, por um lado, a percepção de que havia um conhecimento mais elaborado que não fora manifestado declarativamente em sua totalidade na atividade escrita inicial, como é possível perceber no $1^{0}$ registro escrito do professor Mauro, bem como em outra imagem apresentada no 20 encontro (MF4-P4), destacando a natureza diversa dos saberes que envolvem a temática.

${ }^{9}$ Anotações de caderno de campo do encontro do dia 02.04.16.

História \& Ensino, Londrina, v. 24, n. 1, p. 83-110, jan./jun. 2018 
Quadro 3 - Registros produzidos pelo professor Mauro

\begin{tabular}{|l|l|l|l|}
\hline $\begin{array}{c}\text { O que é } \\
\text { imagem? } \\
\text { (M-P1) }\end{array}$ & $\begin{array}{c}\text { O que é } \\
\text { fotografia? } \\
\text { (M-P2) }\end{array}$ & $\begin{array}{l}\text { Como a fotografia } \\
\text { pode ser utilizada } \\
\text { no ensino de } \\
\text { História (M-P3) }\end{array}$ & $\begin{array}{c}\text { MF4-P4 } \\
\text { (legenda da foto: "Sem } \\
\text { título") }\end{array}$ \\
\hline $\begin{array}{l}\text { "É o que nos } \\
\text { chega através } \\
\text { dos sentidos, } \\
\text { sobretudo a } \\
\text { fala e a visão". }\end{array}$ & $\begin{array}{l}\text { "É um } \\
\text { registro da } \\
\text { imagem } \\
\text { baseado na } \\
\text { quantidade } \\
\text { de luz". }\end{array}$ & $\begin{array}{l}\text { "Através de uma série } \\
\text { de investigações que } \\
\text { possibilitem sua } \\
\text { compreensão: época, } \\
\text { local, costumes, etc. } \\
\text { Pode ser utilizada num } \\
\text { trabalho comparativo, } \\
\text { tendo em vista a } \\
\text { percepção de } \\
\text { continuidades e } \\
\text { rupturas, permanências } \\
\text { e mudanças ao longo da } \\
\text { história". }\end{array}$ \\
\hline
\end{tabular}

\section{Fonte: Autor.}

Com esses dados de análise em mãos, no 20 encontro, foi realizada uma exposição teórica sobre os fundamentos das questões que envolvem os regimes de visualidade na contemporaneidade, sempre norteada pelas fotografias produzidas pelos professores. A partir da ideia de que a mesma é, basicamente, uma síntese que oferece traços, cores e outros elementos visuais, introduziram-se alguns aspectos dos debates que, no campo da História, vêm sendo travados em torno dos usos da fotografia como fonte histórica. Aqui, se enfatizou, por um lado, o ato fotográfico como prática social, e, por outro, o posicionamento necessário do pesquisador diante da imagem fotográfica (LEITE, 1993).

Nesse sentido, destacou-se a produção fotográfica como sistemas de signos ou símbolos que transmitem significado do testemunho ao leitor, ou da fotografia aos órgãos visuais do pesquisador, criando textos intermediários orais/verbais, seja das diferentes personagens fotografadas ou contemporâneas à fotografia, seja dos grupos descritos, uma vez que "nunca olhamos apenas uma coisa, estamos sempre olhando para as relações entre as coisas e nós mesmos" (LEITE, 1993, p. 31), e como os historiadores têm considerado as imagens estáticas e em movimento no contexto de uma cultura visual, deslocando-se a atenção das fontes visuais para a visualidade (MENEZES, 2007). Assim, o olhar voltou-se para a percepção daquele sujeito que, a partir de indícios, começava a "aparecer" por trás da máquina 
fotográfica. Mas não só. Também se imaginou que pessoas poderiam consumir essas imagens. A ênfase recaiu na polissemia dos sentidos, que é intrínseca ao olhar mecânico e à inserção dessas imagens em uma economia visual.

Knauss (2006), apresentando o processo de afirmação das imagens como fonte para o historiador, a partir da década de 1980, nos Estados Unidos, apresenta uma definição de cultura visual que foi considerada como aporte para as discussões e atividades propostas no curso. Segundo o autor, de pictorial turn, expressão cunhada com a leitura de Richart Rorty, que introduziu a ideia de linguistic turn ${ }^{10}$ na década de 1960, passou-se, na crítica das artes e das formas culturais, a dar destaque aos diversos modelos de "textualidade" e discursos, tendo alguns autores sublinhado "a importância assumida pelos modos de ver e pela experiência visual como paradigmas de nossa época" (KNAUSS, 2006, p. 106-107). Assim,

Nessa perspectiva, importa, sobretudo, não tomar a visão como dado natural e questionar a universalidade da experiência visual. Trata-se de abandonar a centralidade da categoria de visão e admitir a especificidade cultural da visualidade para caracterizar transformações históricas da visualidade e contextualizar sua visão (KNAUSS, 2006, p. 107).

No caso específico da fotografia, Lima e Carvalho (2009) destacam que sua abordagem como fonte exige que se entenda a diversidade de usos, que gerou arquivos e coleções encontradas hoje não só em arquivos, museus, bibliotecas, etc., mas também nos seus locais de origem de produção ou no caminho final de sua circulação. Segundo as autoras,

É necessário ainda deixar claro que tais circuitos precisam ser compreendidos de modo que a fotografia não seja descolada de seus contextos de produção circulação, consumo, descarte e institucionalização. O contexto da imagem fotográfica não é seu conteúdo, mas o modo de apropriação da imagem como artefato (LIMA; CARVALHO, 2009, p. 35).

\footnotetext{
10 Richard Rorty (1992) caracterizou a história da Filosofia como uma série de turns (viradas) nas quais uma nova gama de problemas viria à tona, enquanto outra entrava em decadência ou desaparecia gradualmente. O linguistic turn, ou virada linguística, seria, na época de publicação de suas reflexões (anos de 1960), uma de suas etapas mais recentes. De acordo com Rorty, a virada linguística teve uma complexa repercussão em outras disciplinas das chamadas Ciências Humanas. O pictorial turn (ou "virada pictórica") trouxe a ideia de que "a experiência visual (ou a literacia visual) não é totalmente explicável através do modelo da textualidade" (MITCHELL, 1994, p. 16 apud NÓVOA, 2000, p. 01).
} 
Um elemento fundamental a ressaltar no trabalho desenvolvido referese à necessidade de abordar, paralelamente às questões teóricas e práticas abrangendo o ato de fotografar e a construção do Olhar, o planejamento didático envolvendo o uso de imagens pelos docentes. Assim, na parte final do segundo encontro, solicitou-se a produção de um plano de aulas que, de alguma forma, dialogasse com os conteúdos que estavam sendo abordados até aquele momento no curso. Foi solicitada a elaboração de uma proposta de uso de imagem com os alunos (pintura, gravura ou fotografia) levando-se em consideração os conteúdos curriculares propostos em seus planejamentos anuais, a partir de um roteiro norteador da atividade. O objetivo era, a partir daquele momento, aproximar as reflexões conceituais da razão pedagógica (ANHORN, 2003), ou seja, das especificidades da disciplina escolar de História, da escola e da sala de aula, real locus de trabalho dos docentes.

No terceiro encontro, iniciou-se a abordagem dos usos de gravuras e fotografias no Ensino de História com a intenção, ainda, de dar destaque aos elementos tangentes à razão pedagógica. Adotando a ideia de trabalhar com modelos como fonte de reflexão sobre a prática docente, os participantes foram convidados a "assumirem" o lugar de "alunos" de um 90 ano ${ }^{11}$ e a realizarem uma atividade de leitura de gravuras e fotografias do século XIX ${ }^{12}$ com o objetivo de obter informações sobre como era a vida dos escravos no Brasil naquele período, mais especificamente em regiões produtoras de café como o Rio de Janeiro e Minas Gerais.

Um conjunto de imagens foi apresentado ao grupo que, em duplas, seguiu um roteiro de leitura de documento imagético elaborado a partir de Trépat (1996) e Prats (2011) o qual, em linhas gerais, possibilitou que fossem enfocados três níveis de análise do documento imagético: a análise morfológica, considerando os aspectos técnicos e formais da imagem; a

\footnotetext{
${ }^{11}$ Aqui, pautou-se pela ideia de "simetria invertida" para descrever um aspecto da profissão e da prática que inclui os conceitos de homologia de processos e o que Donald Schön denomina "play in a hall of mirrors" (ALARCÃO, 1996). Ressalto, também, que, para a preparação da sequência proposta, pautei-me pelo conceito de situações de dupla conceitualização (LERNER, 2007).

12 Foram apresentados exemplares das obras de Victor Frond, J. Christiano, W. Read, Debret, Harro-Haring e Rugendas. A seleção foi feita seguindo-se o critério de trabalhar com imagens de uso corrente nos livros didáticos, como é o caso da produção de Debret e Rugendas, em contraste com registros que dificilmente se tem acesso, como a produção de Harro Haring e Victor Frond.
} 
análise sintática do conteúdo, que significa dizer o que foi fotografado e como cada elemento se articula com os demais; e, por último, a análise do significado (PRATS, 2011, p. 76).

Na preparação da atividade, também foram considerados os princípios da metodologia de ensino baseada na pesquisa, principalmente a partir de García-Pérez e Iglésias (1994), Pozo (1998), Prats (2006) e Torruella e Cardona (2011), e que remete ao uso de estratégias que possibilitem ao estudante experienciar situações didáticas que tomam como elemento central as práticas de investigação investidas pelo historiador em seu fazer. Já nos idos da década de 1980, Marson (1986) apresentou alguns dos princípios dessa perspectiva no contexto de reflexões sobre a relação entre a Teoria da História e o Ensino de História. Em sua reflexão sobre os elementos que são comuns ao historiador e ao professor de História, o autor deu relevo aos princípios que movem as noções e categorias (a integração, a adequação e a causalidade, generalização e objetividade) para se chegar a uma explicação completa, objetiva e racional. Prats, posteriormente, justifica a consideração desses aspectos, destacando que

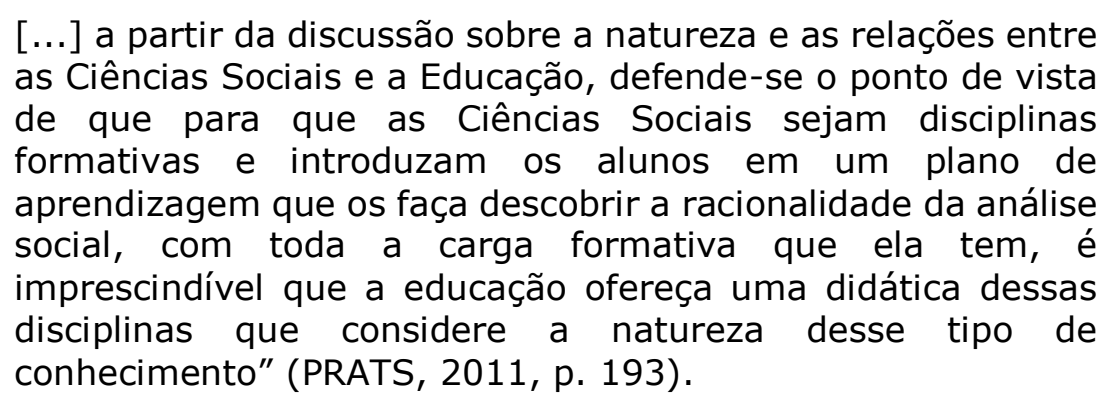

Depois de realizarem as atividades previstas - análise das imagens; socialização dos dados obtidos; mapeamento de questões de investigação motivadas pela leitura das imagens; elaboração, em duplas, de suposições de respostas às questões de investigação; e listagem das fontes bibliográficas com as quais poderiam ser respondidas as questões -deu-se início à tematização, enfocando, agora, as condições didáticas da tarefa pari passu às questões que envolvem o uso de imagens estáticas no ensino de História, tais como sugerem Molina (2007) e Gejão (2009). O plano foi apresentado pela maioria dos participantes e, a partir de intervenções específicas e 
coletivas, gerou-se um percurso de produção, com idas e vindas, que se tornou bastante produtivo e muito revelador.

A seguir, analisar-se-á o percurso de um dos professores, tecendo considerações em torno não só das três versões produzidas de seu plano de aula, mas da relação entre essas produções e aquelas que enfocaram apenas os conteúdos específicos do curso (imagem e fotografia), procurando explicitar a complexidade dos saberes que são mobilizados no ato de planejar.

\section{Formar para ensinar História utilizando imagens: o exercício do diálogo}

Como apontado anteriormente, no $1^{0}$ encontro, os professores responderam a três questões apresentadas pela autora (P1, P2 e P3), as quais foram retomadas ao final do curso com o objetivo principal de potencializar o papel mediador da língua escrita nos processos de pensamento, uma vez que, na atividade de reescrita, a natureza dialógica da produção textual pode ganhar uma conotação especial, pois o autor acaba, necessariamente, tornando-se o leitor de seu próprio texto. Alternadamente, como leitor e coleitor (SAUTCHUK, 2003), o docente, pelas possibilidades oferecidas pelo registro escrito, estabelece uma relação interlocutiva com suas próprias ideias e passa a ver a si mesmo como um "outro". Imbuído desse outro olhar, ele se aproxima de seus escritos como exemplares de seu pensamento e relaciona-se de forma dialética com o mesmo.

Importa destacar que, na análise empreendida, não foi considerado o registro escrito produzido como a expressão absoluta dos saberes de seu autor. Pelo contrário, a produção, entendida em uma perspectiva enunciativa, está inserida em um circuito de produção discursiva, e, antes de tudo, devido ao papel mediador e constitutivo da língua escrita, apresenta apenas indícios de reflexões muito mais intensas e profundas levadas a cabo por aquele que a produziu. Muito embora seja possível identificar os indícios que remetem às concepções de História, de ensino e de aprendizagem da História, e de Didática, que aparecem imbricados de forma complexa, elegeu-se, para 
apresentação neste artigo, um exercício de análise de aspectos relacionados ao ensino e à aprendizagem da História, tanto pela limitação do espaço, quanto pelo fato de que esse foi o eixo em torno do qual o curso foi ministrado.

Isto posto, apresentam-se, a seguir, as respostas do professor Mauro.

\section{Quadro 4 - Produção1 (MP1), sua retomada (MP6) e os comentários produzidos pelo Prof. Mauro ao compará-las.}

\begin{tabular}{|c|c|c|c|}
\hline Questões & MP1 & MP6 & $\begin{array}{c}\text { Comentários avaliativos } \\
\text { (comparação) } \\
\text { (com }^{13} \\
\text { (produzidos após a finalização do } \\
\text { curso) }\end{array}$ \\
\hline $\begin{array}{l}\text { 1. O que é } \\
\text { imagem? }\end{array}$ & $\begin{array}{l}\text { É o que nos } \\
\text { chega através } \\
\text { dos sentidos, } \\
\text { sobretudo o } \\
\text { tato e a } \\
\text { visão. }\end{array}$ & $\begin{array}{l}\text { Imagem é uma } \\
\text { construção } \\
\text { humana } \\
\text { produzida pelos } \\
\text { sentidos, } \\
\text { sobretudo a } \\
\text { visão. }\end{array}$ & $\begin{array}{l}\text { As respostas são bem parecidas. Ambas } \\
\text { enfatizam os sentidos humanos, } \\
\text { sobretudo a visão. Isto porque o olhar } \\
\text { contribui para a percepção das cores, } \\
\text { formas, peso, sabor, temperatura e } \\
\text { volume dos objetos, cujas referências } \\
\text { estão guardadas na memória. Contudo a } \\
\text { ideia de construção, presente na segunda } \\
\text { resposta, ressalta a importância da } \\
\text { subjetividade diante daquilo que está } \\
\text { sendo observado ou produzido. A maior } \\
\text { parte destas informações veio de leituras } \\
\text { anteriores a este curso, o que não diminui } \\
\text { sua importância, já que funcionou como } \\
\text { pretexto para que a mente trabalhasse e } \\
\text { recuperasse esses dados. Além disso, a } \\
\text { noção de referente adveio dos vários } \\
\text { debates e discussões que tivemos ao } \\
\text { longo do curso "Ensino de História e a } \\
\text { fotografia como linguagem, fonte } \\
\text { histórica e recurso didático". }\end{array}$ \\
\hline $\begin{array}{l}\text { 2. O que é } \\
\text { uma } \\
\text { fotografia? }\end{array}$ & $\begin{array}{l}\text { É um registro } \\
\text { da imagem } \\
\text { baseado na } \\
\text { quantidade } \\
\text { de luz. }\end{array}$ & $\begin{array}{l}\text { Fotografia é uma } \\
\text { combinação de } \\
\text { ponto e linha, } \\
\text { luz e sombra } \\
\text { captadas pelas } \\
\text { lentes de uma } \\
\text { câmera ou } \\
\text { máquina } \\
\text { fotográfica. }\end{array}$ & $\begin{array}{l}\text { Comparando as duas respostas, } \\
\text { percebemos uma mudança significativa } \\
\text { na descrição do conceito ou da definição } \\
\text { de fotografia. Á simplicidade da primeira } \\
\text { superpõem-se as características } \\
\text { inerentes à forma/contorno do objeto ou } \\
\text { paisagem, evidenciados pela segunda. } \\
\text { Ou seja, fotografia é uma técnica que } \\
\text { depende tanto da relação entre "ponto e } \\
\text { linha" como da relação entre "Iuz e } \\
\text { sombra". A importância da luz para a } \\
\text { efetivação da fotografia veio das aulas de } \\
\text { Física e de um curso oferecido pelo } \\
\text { SENAC há aproximadamente dois anos. } \\
\text { Porém, a relevância do par "ponto e }\end{array}$ \\
\hline
\end{tabular}

\footnotetext{
${ }^{13}$ Para a realização dessa comparação, foi fornecida, por escrito, a seguinte consigna ao docente: "Prezado(a) professor(a), leia e compare as respostas fornecidas na atividade 1 , em suas duas versões, e aponte: o que você já sabia antes do início do curso? Que conhecimentos agregou aos saberes que já possuía? Há mais algum elemento que você considera importante acrescentar?"
} 


\begin{tabular}{|c|c|c|c|}
\hline & & & $\begin{array}{l}\text { linha" é oriunda das aulas do curso de } \\
\text { formação continuada "Ensino de História } \\
\text { e a fotografia como linguagem, fonte } \\
\text { histórica e recurso didático", realizado na } \\
\text { UFF - Polo Campos, no primeiro semestre } \\
\text { de 2014. Baseados na bibliografia } \\
\text { apresentada durante as aulas do curso, } \\
\text { coordenado pela professora Dra. Maria } \\
\text { lima, demos mais um passo no sentido do } \\
\text { aprimoramento do conceito de fotografia, } \\
\text { incorporando ao par tradicional "luz e } \\
\text { sombra" a ideia de "ponto e linha". }\end{array}$ \\
\hline $\begin{array}{l}\text { 3. Como a } \\
\text { fotografia } \\
\text { pode ser } \\
\text { utilizada no } \\
\text { ensino de } \\
\text { História? }\end{array}$ & $\begin{array}{l}\text { Através de } \\
\text { uma série de } \\
\text { investigações } \\
\text { que } \\
\text { possibilitem } \\
\text { sua } \\
\text { compreensão: } \\
\text { época, local, } \\
\text { costumes, } \\
\text { etc. Pode ser } \\
\text { utilizada num } \\
\text { trabalho } \\
\text { comparativo, } \\
\text { tendo em } \\
\text { vista a } \\
\text { percepção de } \\
\text { continuidades } \\
\text { e rupturas, } \\
\text { permanências } \\
\text { e mudanças } \\
\text { ao longo da } \\
\text { história. }\end{array}$ & $\begin{array}{l}\text { Elas são fontes } \\
\text { de informações } \\
\text { que refletem } \\
\text { determinados } \\
\text { interesses. } \\
\text { Portanto, podem } \\
\text { ser usadas para } \\
\text { compreendermos } \\
\text { o contexto em } \\
\text { que foram } \\
\text { produzidas, além } \\
\text { das intenções de } \\
\text { quem as } \\
\text { produziu. }\end{array}$ & $\begin{array}{l}\text { Analisando as duas respostas, escritas } \\
\text { em momentos distintos do curso, } \\
\text { constata-se uma diferença significativa } \\
\text { entre elas. A primeira nos remete para a } \\
\text { compreensão dos fenômenos sociais, } \\
\text { tendo em vista a percepção de } \\
\text { continuidades e descontinuidades a partir } \\
\text { de registros imagéticos vinculados a duas } \\
\text { dimensões temporais: passado e } \\
\text { presente. Já a segunda destaca o valor da } \\
\text { intencionalidade subjacente a esses } \\
\text { registros, independente da técnica } \\
\text { utilizada. Ou seja, vale tanto para a a } \\
\text { pintura quanto para a fotografia ou outra } \\
\text { forma específica de capturar a imagem e } \\
\text { registrá-la numa superfície. Isso não } \\
\text { significa que elas sejam excludentes. Pelo } \\
\text { contrário, rasta são respostas } \\
\text { complementares. Sendo assim, o } \\
\text { trabalho em sala de aula deve levar em } \\
\text { consideração esses dois aspectos } \\
\text { relacionados ao registro da imagem, os } \\
\text { quais são por demais importantes para o } \\
\text { entendimento de qualquer processo ou } \\
\text { contexto históricos. }\end{array}$ \\
\hline
\end{tabular}

Fonte: Autor.

A primeira versão traz indícios dos saberes do professor a respeito dos conceitos de imagem e de fotografia antes do início do curso. Nela, o conteúdo parece remeter apenas à consideração de aspectos internos da imagem fotográfica, quase que a apresentando como um registro do real, pelas potencialidades que possui no trabalho de comparação entre exemplares produzidos em diferentes épocas. Em sua primeira definição, a imagem "está" fora do sujeito que olha.

Na segunda versão, é possível perceber a incorporação de elementos abordados em diferentes momentos do curso, apontando para um processo de ressignificações conceituais e deslocando a noção de imagem para o sujeito que a produz. O enunciado produzido aponta outra reconfiguração da 
noção de imagem, definida não apenas em seus aspectos internos, mas deslocando o olhar para questões da autoria e do contexto em que a fotografia foi produzida.

A análise de seus escritos, feita pelo próprio sujeito objeto desta pesquisa, abriu espaço para que o mesmo indicasse relações entre os saberes que já possuía e as ressignificações produzidas no decorrer do curso, fato que resultou em um texto rico e de maior densidade. Independentemente de saber se os conhecimentos que o sujeito manifestou em seu texto escrito foram adquiridos no curso ou não, importa ressaltar que o olhar retrospectivo sobre a própria produção no momento de avaliação permitiu-Ihe sistematizálos e analisá-los em um contexto que favorecesse a percepção de um processo.

Consciente da complexidade das relações entre os saberes relacionados ao "o que" ensinar e aqueles da docência, ao comparar a análise dos escritos das três versões do plano de aula que foram requisitadas e atendidas pelos participantes do curso com as primeiras versões dos seus respectivos planos de aula, algumas indagações guiavam o olhar desta pesquisadora: quais relações seriam estabelecidas por esses sujeitos, entre os conteúdos abordados teoricamente e nos exercícios de produção de imagem, com os saberes que possuíam a respeito do ensino de História?

Ao analisar o processo como um todo (da primeira até a terceira versão do plano de aula), foi possível configurar um quadro das principais características de um processo de reflexão, instaurado dentro de um percurso no qual o "como" fazer ganhou uma relevância diferente.

A seguir apresenta-se a primeira versão do plano de aula de Mauro $(\mathrm{MPA} 1-\mathrm{P} 5)^{14}$.

\footnotetext{
${ }^{14}$ Aqui a sigla de identificação utilizada tem a seguinte conotação: M (Mauro), PA (plano de aula), sendo o número que aparece ao final correspondente àquele da versão do plano de aula.
} 
Quadro 5 - $1^{\text {a }}$ versão do plano de aula do professor Mauro

\section{MPA1-P5 [apresentada no $3^{\circ}$ encontro]}

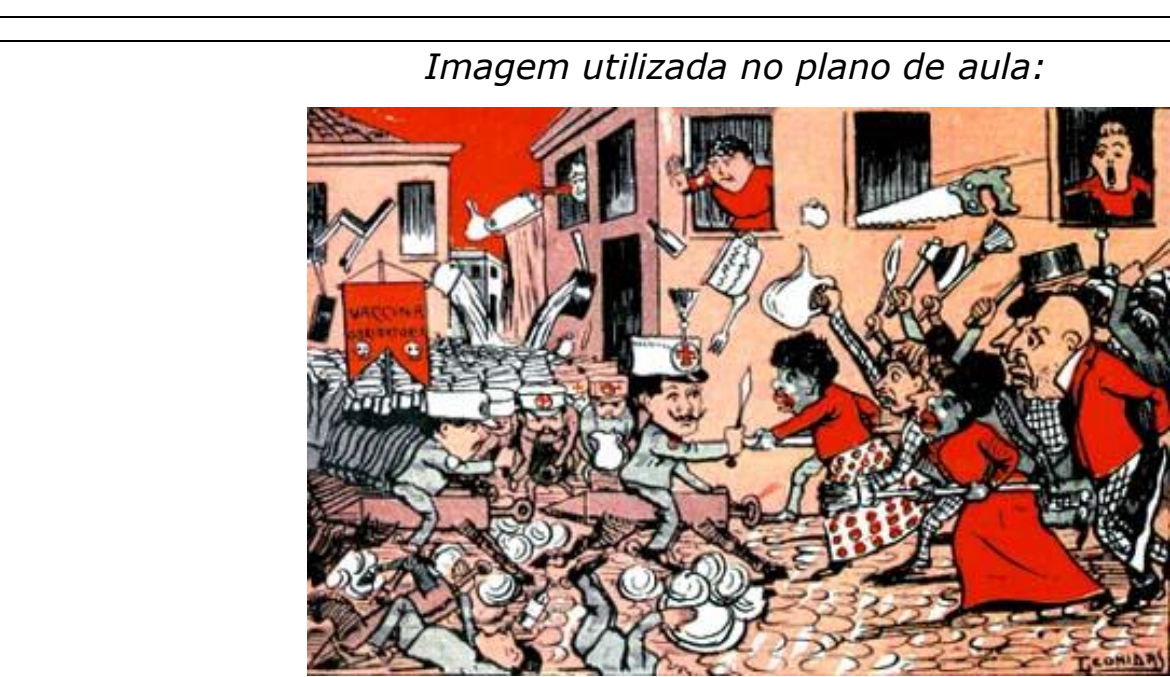

Identificação da imagem: Revolta da Vacina

Autoria: Leônidas Freire

Data de produção: 1904

Local onde está publicada: $O$ Malho

Turma(s) com a(s) qual(is) pretende utilizar: 901 e 902

Conteúdos que pretende abordar:

01. A Revolta da Vacina;

02. As Manifestações Populares de 2013.

Estratégias que mobilizará ao usar a imagem:

01. Breve apresentação da charge de Leônidas Freire;

02. Memorização e registro individual dos elementos constitutivos da imagem;

03. Socialização das lembranças, em grupos de três ou quatro;

04. Reconstrução, por escrito, da cena observada;

05. Reapresentação da charge;

06. Leitura de fragmentos dos textos validados pela imagem.

07. Aula expositiva sobre a Revolta da Vacina;

08. Contextualização do tema.

Fonte: Autor.

Essa produção foi apresentada pelo docente no $3^{\circ}$ encontro e, em orientação individual, no mesmo dia, foram feitas algumas sugestões objetivando possibilitar que o mesmo promovesse uma ressignificação de seus saberes, pela mobilização em um contexto de uso de algumas das noções trabalhadas no curso. A produção de uma tematização que mobilizasse o professor foi desafiadora, tendo em vista a complexidade que se colocou frente à produção apresentada e ao exíguo tempo de diálogo para orientá-lo. 
Á primeira vista, foi possível perceber indícios dos saberes específicos bem diferentes daqueles expressos em relação ao conceito de imagem e fotografia e seus usos no ensino de História. Enquanto na atividade 1, Mauro mobilizou de forma proficiente as definições que consideraram conceitos complexos relacionados à imagem, na CPA1 não foi possível vislumbrar a consideração dos mesmos. O plano de aula apresentado centrava-se no professor, com a lista das ações que seriam realizadas durante todo o processo. Daí a importância de se pensar a formação pautada pelo diálogo entre formadores e sujeitos da formação.

No diálogo com o professor Mauro, ao questionar-Ihe onde estava o aluno com o intuito de fazê-lo deslocar o olhar do ensino para a aprendizagem, colocando em foco o aluno e as ações e aprendizagens que ocorreriam durante o trabalho, centraram-se as reflexões na dimensão das concepções de ensino/aprendizagem entrecruzadas àquelas da História e do uso de imagens.

Foram feitas indagações, também, no concernente às possibilidades da comparação entre dois momentos históricos distintos, pois as mesmas não estavam claras no plano apresentado, uma vez que as manifestações de 2013, às quais se referia tinham um alvo muito diferente daquelas da Revolta da Vacina, em 2010. Além disso, questionou-se, ainda, no sentido de adotar estratégias que tornassem a imagem um documento histórico a ser examinado e problematizado pelos próprios alunos, potencializando o desenvolvimento da noção de empatia histórica e evidência.

Do diálogo estabelecido no terceiro encontro resultou a $2^{a}$ versão do plano de aula (CPA2), a qual segue abaixo. 


\section{Quadro 6 - $2^{a}$ versão do plano de aula}

\section{MPA2-P5 [apresentada no $4^{\circ}$ encontro]}

\section{[mesma imagem de MPA1-P5]}

Conteúdos que pretende abordar:

01. A participação social na Revolta da Vacina e nas manifestações populares ocorridas no Brasil em 2013.

Estratégias que mobilizará ao usar a imagem:

01. Problematizar o tema, baseado na produção fotográfica das manifestações populares de 2013;

02. Ouvir com a turma a música "Vacina Obrigatória", interpretada por Mario Pinheiro;

03. Distribuir a letra da música para os alunos preencherem os espaços em branco, enquanto escutam-na pela segunda vez;

04. Fazer um estudo do vocabulário da época com o auxílio de um dicionário e/ou da internet, em dupla;

05. Apresentar a charge de Leônidas Freitas sobre a Revolta da Vacina;

06. Pedir para as duplas identificarem alguns trechos da letra da música de Mario Pinheiro na imagem produzida por Leônidas Freitas;

07. Responder, coletivamente, as seguintes questões:

- O que a população pensava a respeito da vacinação obrigatória?

- Como as autoridades são retratadas na letra da música?

- A quem é destinada a crítica à vacina obrigatória?

08. Comparar por escrito, individualmente, as formas de manifestações populares, baseados nas fotografias e na charge sobre a Revolta da Vacina.

09. Avaliar a produção escrita e divulgar os resultados para os alunos.

\section{Fonte: Autor.}

Pode-se afirmar que o diálogo foi promissor, pois o professor Mauro inseriu, nesta versão, o termo "problematizar" (item 1) relacionado às reflexões didáticas que contextualizam o ensino de História na perspectiva da investigação. O trabalho desenvolvido na sala com os professores do curso teve início justamente pela problematização de imagens da escravidão (gravuras e fotografias) com questões que induziram à análise estética e à formulação de questões de investigação, as quais conduziram, posteriormente, ao registro de suposições de resposta (em duplas) e posterior mapeamento de fontes bibliográficas que pudessem apoiar a leitura daquelas imagens.

Assim, na ação de formação, "problematizar" implicava em formular indagações a partir das imagens logo no início do trabalho, uma vez que "não existem fatos, nem História, sem um questionamento; neste caso, na construção da História, as questões ocupam uma posição decisiva" (PROST, 2008, p. 75). Apesar de o termo ter sido inserido como sinônimo de 
"contextualizar" e "introduzir", infere-se que sua inserção fornece indícios da reflexão que o professor teceu sobre como relacionar passado e presente, centrando na ideia de revolta significante que, aparentemente, havia estabelecido como eixo para indicar relações entre os dois períodos históricos, conforme evidenciado na proposta de comparação formulada no item 8 de MPA2-P5.

Corrobora a análise a presença de uma estrutura fortemente marcada pela lógica do exercício, em que os estudantes apareciam como executores de tarefas nas quais o resultado tinha pouca relação com o aprender História (AISENBERG, 2013), conforme percebido nas propostas de atividades dos itens 3 e 4 de MPA2-P5, em que o sentido parece estar sendo guiado pelas ideias de "manter a atenção" dos alunos (item 3) e "melhorar a compreensão" pelo "deciframento" do texto (item 4).

Na comparação de MPA1-P5 com MPA2-P5, retomou-se novamente o porquê de relacionar a imagem das manifestações de 2013, de maneira a tematizar o conceito de documento histórico com o enfoque do conceito de imagem e sua relação com o ensino de História, momento em que se pontuou o risco de anacronismo presente no uso daquela imagem, pois ela poderia induzir a pensar as sociedades do passado com conceitos contemporâneos. O diálogo resultou na produção denominada MPA3-P5 que será analisada a seguir.

\section{Quadro 7 - $3^{a}$ versão do plano de aula}

\section{MPA3-P5 [apresentada após o $8^{\circ}$ encontro]}

\section{[mesma imagem de MPA1-P5]}

Conteúdos que pretende abordar:

1. A participação social na Revolta da Vacina

Estratégias que mobilizará ao usar a imagem:

1. Projetar na tela a charge de Leônidas Freitas sobre a Revolta da Vacina a fim de, coletivamente:

1.1 Identificar o cenário, os atores sociais e os elementos da cena;

1.2 Caracterizar as expressões das personagens;

1.3 Levantar alguma(s) hipótese(s) sobre o (s) motivo(s) dessa revolta.

2. Distribuir a letra da música "Vacina Obrigatória", interpretada por Mario Pinheiro para, em duplas e lou grupos de três:

2.1 Preencher os espaços em branco durante a apresentação da música;

2.2 Fazer um estudo do vocabulário da época com o auxílio de um dicionário e/ou da internet;

2.3 Relacionar alguns trechos da letra da música com a imagem produzida por Leônidas Freitas.

3. Aula expositiva sobre a Revolta da Vacina, tendo em vista: 
3.1 Analisar o contexto;

3.2 Verificar a(s) hipótese(s) levantada(s) pelos alunos;

3.3. Apresentar os motivos e o desfecho dessa revolta.

4. Responder, individualmente, as seguintes questões:

- O que a população pensava a respeito da vacinação obrigatória?

- Como as autoridades são retratadas na letra da música?

- A quem é destinada a crítica à vacina obrigatória?

- Comparar as condições de saúde e higiene do início do século XX com as condições de saúde e higiene hoje em dia.

5. Avaliar a produção escrita e divulgar os resultados para os alunos.

\section{Fonte: Autor.}

A centralidade ainda permanece sobre o ensino no plano de aula apresentado, no qual predominou a tendência na descrição daquilo que o professor fará, com poucas indicações de situações em que os alunos teriam voz e quais processos reflexivos seriam potencializados. No entanto, percebese uma mudança substancial na proposta de análise inicial da imagem, que incorporou as estratégias de leitura na perspectiva do documento histórico, trabalhadas nos primeiros encontros do curso. Embora o sujeito a quem as orientações se dirijam ainda seja o professor, o docente negritou a palavra "coletivamente", destacando que a realização da tarefa envolveria os alunos.

Na perspectiva apresentada no curso, destacou-se o papel mediador do docente que, a priori, planejaria situações em que os alunos seriam incentivados a realizarem exercícios de descrição, mobilizando conhecimentos anteriores e registrando suas suposições. Todavia, as ações dos alunos nesse plano de aula não foram detalhadas, o que pode apontar para a necessidade de se refletir mais profundamente sobre os processos cognitivos a serem envolvidos em toda a atividade proposta.

Outro elemento importante observado foi a retomada da aula expositiva, presente em MPA1-P3, mas que havia sido retirada na versão seguinte. Nessa última versão, o docente reinsere a mesma a partir do questionamento feito sobre a necessidade de se promoverem sistematizações periódicas dos saberes que os estudantes elaborariam ao longo do processo de estudo da imagem apresentada.

Ao comparar as versões do plano de aula (MPA1, MPA2 e MPA3) àquelas da Produção 1 (MP1, MP6, e comentários avaliativos), bem como aos saberes que se explicitaram nas fotografias produzidas por Mauro, vislumbrase que os saberes relacionados à imagem se encontravam apartados da 
proposta apresentada para a ação docente em sala de aula, indicando que o domínio teórico de um certo conteúdo não implica, necessariamente, em uma "tradução" didática mecânica, o que pode corroborar para desmistificar a ideia de que o domínio conceitual de um certo conteúdo implica, necessariamente, em uma prática de ensino que avance em relação a concepções empiristas de ensino-aprendizagem.

Os indícios destacados podem remeter a todo um processo de reflexão, que é gradual porque complexo e multifacetado sobre o "como ensinar", configurado no encontro teórico de referenciais da Teoria da História, da Historiografia, da Didática geral e específica, além dos objetivos do ensino de História na escola, realçando a função formativa do mesmo. No caso específico do trabalho com imagens, concorreram, ainda, conhecimentos relacionados à Filosofia, à Sociologia e à Semiótica.

\section{Considerações Finais}

A comparação das três produções e da análise que Mauro empreendeu de sua própria produção, reforçam a ideia de que os professores não se limitam a executar currículos, mas também os elaboram, definem e reinterpretam a partir do que pensam, do que acreditam e daquilo que valorizam (PIMENTA, 2002). Além disso, não se pode esquecer que as reflexões tecidas pelo professor de História encontram-se imersas na cultura escolar e, necessariamente, marcadas pela forma escolar (VINCENT; LAHIRE; THIN, 2001) e pelos constrangimentos da disciplina escolar.

A possibilidade de produzir registros durante o curso e de retomá-los, revisando-os em contextos mediados pela escrita e pelo diálogo com o formador, pareceu potencializar o exercício de reflexão sobre o próprio trabalho, elemento considerado central em práticas que visam a formação de docentes na perspectiva do intelectual crítico reflexivo. Pela sua qualidade de memória, foi possível instaurar, a partir do registro escrito, uma relação de diálogo do sujeito com seus saberes de maneira consciente e mediada. 
Observando a avaliação que Mauro faz de sua produção e as várias versões do plano de aula que elaborou, vem à tona a percepção de que o processo reflexivo exige tempo e contexto. É preciso, também, um fazer situado, inserido na escola e no diálogo com o formador de maneira significativa. A escrita, por suas qualidades de fixidez e de registro, pode favorecer e apoiar a configuração desse processo de criação em que se transforma a ação docente em contextos dinâmicos.

Ressalta-se, por conseguinte, que as práticas de formação em cursos de curta duração necessitam inserir situações em que o professor possa tornar sua própria produção, configurada em processo, como objeto de análise. Neste texto, elencaram-se algumas das potencialidades que 0 registro escrito pode oferecer nesse sentido, destacando que a relação mediada entre o pensamento e a linguagem inclui a palavra como signo, instrumento convencional de natureza social, e a analogia básica entre signo e instrumento repousa na função mediadora que os caracterizam (VIGOSTSKI, 2001). Esse pressuposto é o que permite afirmar a necessidade de promover situações de diálogo, mediadas pela escrita como estratégia favorecedora de processos de formação em serviço, destacando sua característica de instrumento cultural de aprendizagem (FREITAS, 2010).

Assim, deve-se investir na potencialidade da agência docente como forma de combate às práticas tecnicistas e aos projetos que as referendam, uma vez que "a agência docente é um empreendimento agonístico, audacioso, marcado por incerteza, resolução e tentativa, um esforço que pode agir às margens da verdade científica sobre nós próprios" (PIGNATELLI, 1994).

\section{Referências}

AISENBERG, Beatriz. Usos de la escritura en la enseñanza de la Historia. Revista Opsis, Catalão, GO, v. 13, n. 1, p. 45-52, jan. /jun. 2013.

ALARCÃO, Isabel. Formação reflexiva de professores: estratégias de supervisão. Porto: Ed. Porto, 1996. 
ANHORN, Carmen Teresa Gabriel. Um objeto de ensino chamado História: a disciplina de História nas tramas da didatização. Rio de Janeiro:

Departamento de Educação, Pontifícia Universidade Católica, 2003.

BENJAMIN, Walter. Obras escolhidas: magia, arte, técnica e política. São Paulo: Brasiliense, 1985. v. 1.

CAIMI, Flávia E. Aprendendo a ser professor de história. Passo Fundo: Ed. UPF, 2008.

CHARLOT, Bernard. Relação com o saber, formação de professores e globalização: questões para a educação hoje. Porto Alegre: Artmed, 2005

FREITAS, Maria Teresa de. Letramento digital e formação de professores. Educação em Revista, Belo Horizonte, v. 26, n. 3, p. 335-352, dez. 2010.

GARCÍA-PÉREZ, Francisco F.; IGLESIAS, Francisco Javier Merchán; Una metodología basada en la idea de investigación para la enseñanza de la historia. In: ALDEROQUI, Silvia; AISENBERG, Beatriz, (Coord.). Didáctica de las Ciencias Sociales: aportes y reflexiones. Buenos Aires: Paidós, 1994. p. 183-204.

GEJÃO, Natália G. A fotografia como mediador cultural na construção do conhecimento histórico escolar. Antíteses, Londrina, v. 2, n. 3, p. 257-267, jan. / jun. 2009.

KNAUSS, Paulo. O desafio de fazer História com imagens: arte e culutra visual. ArtCultura, Uberlândia, v. 8, p. 97-115, jan. /jun. 2006.

LARROSA, Jorge. Notas sobre a experiência e o saber da experiência. Revista Brasileira de Educação, Rio de Janeiro, n. 19, p. 20-28, jan. /abr. 2002.

LAVILLE, Claude. A construção do saber: manual de metodologia da pesquisa em ciências humanas. Porto Alegre: Artes Médicas, 1999.

LEITE, Miriam Moreira. Retratos de família. São Paulo: Edusp/Fapesp, 1993.

LERNER, Delia. Situações de "dupla conceitualização". In: CARDOSO, Beatriz et. al. Ensinar: tarefa para profissionais. Rio de Janeiro: Record, 2007.

LIMA, Solange Ferraz; CARVALHO, Vânia Carneiro de. Fotografia: usos sociais e historiográficos. In: PINSK, Carla B.; LUCA, Tania de. O historiador e suas fontes. São Paulo: Contexto, 2009. p. 29-60.

MARSON, Adalberto. Reflexões sobre o procedimento histórico. In: SILVA, Marcos A. Repensando o ensino de História. Rio de Janeiro: Marco Zero, 1986. p. 37-67. 
MENEZES, Ulpiano B. de. Fontes visuais, cultura visual, História visual: balanço provisório, proposta cautelares. Revista Brasileira de História, São Paulo, v. 23, n. 45, p. 11-36, 2007.

MOLINA, Ana Heloisa. Ensino de História e imagens: possibilidades de pesquisa. Domínios da Imagem, Londrina, ano 1, n. 1, p. 15-29, nov. 2007.

MONTEIRO, Ana Maria F.C. A história ensinada: algumas configurações do saber escolar. Revista História \& Ensino, Londrina, v. 9, p. 9-35. out. 2003

NóVOA, Antonio. As palavras das imagens: retratos de professores (século XIX-XX). Atlântida: Revista de Cultura, v. 46, p. 101-122, 2000. Disponível em: <http://repositorio.ul.pt/bitstream/10451/671/1/21231_16461002_101-122.pdf>. Acesso em: 1 abr. 2018.

PIGNATELLI, Frank. Que posso fazer? Foucault e a questão da liberdade e da agência docente. In: Silva, Tomaz Tadeu (Org.). O sujeito da educação estudos foucaultianos. Petrópolis, RJ: Vozes, 1994.

PIMENTA, Selma Garrido. Professor reflexivo: construindo uma crítica. In: PIMENTA, Selma Garrido; GHEDIN, Evandro (Org.). Professor reflexivo no Brasil: gênese e crítica de um conceito. São Paulo: Cortez, 2002.

POUPART, Jean et al. A pesquisa qualitativa: enfoques epistemológicos e metodológicos. Petrópolis: Vozes, 2010.

POZO, Juan I. Solução de problemas: aprender e resolver, resolver para aprender. Porto Alegre: Artes Médicas, 1998.

PRATS, Joaquín. Ensinar História no contexto das Ciências Sociais: princípios básicos. Revista Educar, Curitiba, n. esp., p. 191-218, 2006.

PRATS, Joaquín. Geografia e História: investigación, innovación y buenas prácticas. Barcelona: Graó, 2011.

PROST, Antoine. Doze lições sobre a História. Campinas: Autêntica, 2008.

RORTY, Richard M. The linguistic turn: essays in philosophical method. Chicago: University of Chicago Press, 1992.

SAUTCHUK, Inez. A produção dialógica do texto escrito: um diálogo entre o escritor e o leitor interno. São Paulo: M. Fontes, 2003.

TARDIF, Maurice. Saberes profissionais dos professores e conhecimentos universitários: elementos para uma epistemologia da prática profissional dos professores e suas consequências em relação à formação para o magistério. Revista Brasileira de Educação [online], Rio de Janeiro, n. 13, p. 5-24, 2000. 
TARDIF, Maurice; RAYMOND, Danielle. Saberes, tempo e aprendizagem do trabalho no magistério. Educação \& Sociedade, São Paulo, ano 21, n. 73, p. 209-244, dez. 2000.

TORRUELLA, Maria Feliu; CARDONA, Francesc Xavier Hernández. 12 ideas claves: enseñar y aprender Historia. Barcelona: Graò, 2011.

TRÈPAT, Cristófol A. Procedimientos en História: un punto de vista didáctico. Barcelona: Graó, 1996.

VINCENT, Guy; LAHIRE, Bernard; THIN, Daniel. Sobre a história e a teoria da forma escolar. Educação em Revista, Belo Horizonte, n. 33, p. 7-47, jun. 2001.

VYGOSTY, L. S. Pensamento e linguagem. São Paulo: Cortez, 2001.

Recebido em 02 de novembro de 2017

Aprovado em 13 de abril de 2018 